Jurnal Tanah dan Sumberdaya Lahan Vol 7 No 2 : 273-282, 2020

e-ISSN:2549-9793, doi: 10.21776/ub.jts1.2020.007.2.11

\title{
PEMETAAN SEBARAN STATUS UNSUR HARA N, P DAN K PADA LAHAN SAWAH DI KECAMATAN TUREN, KABUPATEN MALANG
}

\section{Mapping of Nitrogen, Phospor and Pottasium Nutrients on Rice Fields in Turen District, Malang Regency}

\author{
Christanti Agustina*, Mochtar Lutfi Rayes, Marinda Kuntari \\ Jurusan Tanah, Fakultas Pertanian, Universitas Brawijaya Jl. Veteran No.1, Malang, Jawa Timur 65145 \\ *Penulis korespondensi: christanti.ag@ub.ac.id
}

\begin{abstract}
The availability of nutrients plays a role in increasing crop productivity, especially primary macronutrients (nitrogen, phosphorus and potassium). This research aimed to measure the content of macronutrients and crop productivity in the rice field and to map the nutrients status. The study was conducted from July to October 2019 in Turen District. The survey method based on the boundary of the land mapping unit was used to collect field data in this study. The mapping of nutrient status created using IDW, which was interpolated data based on the assumption that values of unsampled points can be predicted as the weighted average of known values within the neighbourhood. The results showed that the nitrogen status are very low to low status $(0.08 \%$ $0.18 \%)$, the phosphorus status are very low to low status $\left(4.5 \mathrm{mg} \mathrm{kg}^{-1}-12.37 \mathrm{mg} \mathrm{kg}^{-1}\right)$ and the potassium status are at low, moderate to high status $\left(0.25 \mathrm{cmol} \mathrm{kg}^{-1}-0.71 \mathrm{cmol} \mathrm{kg}^{-1}\right)$. The availability of nitrogen nutrient is classified as S2, the availability of phosphorus nutrient is classified as S3, and the availability of potassium nutrient is classified as S1. The availability of nitrogen, phosphorus and potassium can be increased through fertilization in accordance with the needs and recommendations. The effect of the status of nitrogen, phosphorus and potassium at the end of planting on crop productivity was indicated by the regression coefficient of $\mathrm{R}^{2}=0.0826$.
\end{abstract}

Keywords: nitrogen, nutrient status, phosphorus, potassium, productivity

\section{Pendahuluan}

Kecamatan Turen yang terletak di Kabupaten Malang merupakan salah satu penyangga produksi pangan. Pada tahun 2014, Kecamatan Turen tercatat memiliki hasil produksi pangan tertinggi dibandingkan dengan kecamatan lain di Kabupaten Malang (BPS, 2014). Turen dengan luas 6.582,62 ha didominasi oleh penggunaan lahan pada sektor pertanian seperti, sawah (2.318 ha), tegalan (2.111,2 ha), kebun (770,8 ha) dan sisanya merupakan pemukiman dan semak belukar. Pada tahun 2015 - 2018 produktivitas padi di lokasi penelitian mengalami penurunan dari 7,44 $\mathrm{t}$ ha-1 menjadi 4,5 $\mathrm{t} \mathrm{ha}^{-1}$. Hal ini disebabkan oleh luas panen tanaman padi berkurang dari 2.424 ha menjadi 2.318 ha (BPS,
2019). Fakta lain dikemukakan oleh petani setempat yang menyatakan bahwa terdapat perbedaan kondisi kesuburan tanah di setiap lahan pertanian, sehingga diindikasikan sebagai penyebab penurunan dan ketidakmerataan produksi pertanian. Salah satu penyebab adanya perbedaan kondisi kesuburan tanah disebabkan oleh perbedaan pengelolaan lahan oleh petani. Penggunaan pupuk yang tidak tepat berdampak pada tingkat kesuburan tanah (Notohadiprawiro, 2006).

Secara umum, petani memberikan unsur hara makro primer $(\mathrm{N}, \mathrm{P}$, dan $\mathrm{K})$ dalam bentuk pupuk Urea, pupuk ZA, pupuk SP-36, pupuk $\mathrm{KCl}$ dan pupuk Phonska untuk mendukung produktivitas tanaman. Ketersediaan unsur hara ini ditentukan oleh pengolahan tanah, 
pengairan, pemupukan, dan pengembalian seresah tanaman (Sharma and Bhushan, 2001). Berdasarkan hasil wawancara di Kecamatan Turen, petani masih belum mengetahui mengenai status hara yang ada di lahan pertanian mereka. Petani mengaplikasikan pupuk hanya berpedoman pada pengalaman yang dimiliki dan bukan berdasarkan keadaan tanah serta kebutuhan tanaman. Pemupukan tidak berdasar yang dilakukan petani ini perlu diperbaiki serta perlu diberi informasi mengenai status unsur hara lahannya agar penambahan pupuk dapat dimanfaatkan untuk mempertahankan kesuburan tanah dalam rangka meningkatkan produktivitas secara berkelanjutan serta meningkatkan pendapatan.

Hasil analisis hara di suatu lahan dapat disajikan dalam bentuk peta sehingga memudahkan petani untuk mendapatkan informasi kesuburan tanah pada suatu lahan pertanaman. Kadar unsur hara tanah perlu diketahui dalam penentuan kebutuhan unsur hara tanaman untuk menentukan secara pasti kebutuhan tanaman terhadap masing-masing unsur hara. Oleh sebab itu perlunya dilakukan pemetaan unsur hara khususnya unsur hara makro N, P dan K dengan memanfaatkan Sistem Informasi Geografis (SIG) dengan output untuk mengetahui sebaran ketiga unsur hara makro tersebut di wilayah Kecamatan Turen, Kabupaten Malang.

\section{Bahan dan Metode}

\section{Tempat dan waktu penelitian}

Penelitian ini dilaksanakan pada bulan Juli sampai dengan Oktober 2019 di Kecamatan Turen Kabupaten Malang, Jawa Timur. Analisis Sistem Informasi Geografis (SIG) dilakukan di Laboratorium Pedologi dan Sistem Informasi Sumberdaya Lahan (PSISDL), Jurusan Tanah, Fakultas Pertanian, Universitas Brawijaya. Analisis unsur hara N, P dan K dilakukan di Laboratorium Kimia, Jurusan Tanah, Fakultas Pertanian Universitas Brawijaya.

\section{Alat dan bahan}

Alat yang digunakan dalam penelitian Software ArcGIS 10.3, Global Positioning System (GPS), bor, Plastik ukuran $1 \mathrm{~kg}$, label, ayakan, timbangan, labu ukur, labu Kjeldhal, Flame photometer, Spektrometer Bausch \& Lomb 20 G,
Kertas saring whatman 42. Bahan yang digunakan dalam penelitian contoh tanah, peta Rupa Bumi Indonesia skala 1:25.000 lembar Turen 1607-432, DEM Alos Palsar 12,5 m, Peta Geologi skala 1:100.000 Lembar Turen 1607-4.

\section{Metode}

Metode pengambilan data lapangan dalam penelitian ini menggunakan metode survei. Metode survei secara fisiografi dipilih untuk pengamatan kondisi lahan dan pengambilan contoh tanah pada 8 (delapan) Satuan Peta Lahan (SPL). Peta SPL disusun berdasarkan batas-batas landform dari area yang akan disurvei. Lahan yang memiliki karakteristik landform (lahan) yang sama akan dikelompokkan dalam satu satuan peta lahan. Pengambilan contoh tanah di delapan SPL dilakukan pengulangan sebanyak tiga titik pengamatan, sehingga total terdapat 24 titik pengamatan yang tersebar di seluruh lokasi penelitian. Pelaksanaan penelitian dilakukan dengan beberapa tahapan kegiatan yaitu kegiatan pra survei, kegiatan pengambilan data lapangan (ground check), kegiatan analisis laboratorium dan kegiatan analisis data. Kegiatan pengambilan data lapangan dilakukan di Kecamatan Turen. Analisis laboratorium dilakukan di Laboratorium Kimia Tanah, Jurusan Tanah, Fakultas Pertanian, Universitas Brawijaya.

Kegiatan persiapan survei ini berisi wawancara terhadap petani yang berada di lahan, overview keseluruh daerah survei dengan melakukan pengecekan terhadap hasil peta dasar yang ada, mengurus perijinan penelitian di lokasi pengambilan contoh, mengumpulkan data sekunder, seperti peta lereng, peta landform, peta landuse, dan peta administrasi. Pengambilan contoh tanah di lapangan diambil di setiap SPL (Satuan Peta Lahan). Setiap SPL diambil 3 titik pengamatan untuk diambil contoh tanah untuk dianalisis, sehingga terdapat 24 titik pengamtan yang diamati. Penentuan titik ini berdasarkan kondisi fisiografis lahan di lokasi penelitian dalam menentukan titik pengambilan contoh tanah, menyusun jadwal survei dan menyiapkan peralatan survei. Pengambilan contoh tanah pada titik yang telah ditentukan di peta SPL dengan menggunakan bor tanah dengan kedalaman $0-20 \mathrm{~cm}$ dan contoh tanah diambil $1 \mathrm{~kg}$ serta dimasukkan kedalam kantong 
plastik lalu diberi label. Kegiatan survei lapangan lainnya yang dilakukan adalah pengambilan data produksi tanaman. Pengambilan data produksi diperoleh dari wawancara terdapat 8 petani (responden). Contoh tanah yang telah diambil selanjutnya dianalisis Kadar N, P dan $\mathrm{K}$ di laboratorium Kima Tanah, Fakultas Pertanian, Universitas Brawijaya. Parameter pengamatan berupa $\mathrm{N}$-total (\%) dengan metode destilasi makro Kjeldahl (Bremner, 1960), P-tersedia (mg $\mathrm{kg}^{-1}$ ) dengan metode analisis Bray I (Bray and Kurtz, 1945) dan K-dd ( $\left.\mathrm{cmol} \mathrm{kg}^{-1}\right)$ dengan metode analisis $1 \mathrm{~N}$ NH4OAc $\mathrm{pH}$ 7. Hasil analisis tanah di laboratorium diklasifikasikan menjadi beberapa kriteria menurut Djaenuddin et al. (2003), yaitu sangat rendah, rendah, sedang, tinggi dan sangat tinggi untuk status unsur hara $\mathrm{N}, \mathrm{P}$ dan $\mathrm{K}$ (Tabel 1). Informasi status hara masing-masing titik pengamatan ditambahkan ke dalam attribut peta yang mewakili setiap SPL dan selanjutnya akan diolah menjadi peta status hara N, P dan K. Pembuatan peta sebaran status unsur hara $\mathrm{N}, \mathrm{P}$ dan $\mathrm{K}$ dilakukan dengan menggunakan metode Interpolasi IDW, kemudian diklasifikasikan ke dalam tiga kelas dengan menggunakan acuan dari Djaenuddin $e t$ al. (2003). Kadar unsur hara N, P dan K di setiap Satuan Peta Lahan (SPL) dihubungkan dengan kelas kesesuaian produktivitas tanaman padi (Tabel 2). Kelas kesesuaian produktivitas tanaman dibagi dalam empat kelas menurut FAO (1993), yaitu, S1 (80 - $100 \%)$, S2 (60 - 80 $\%)$, S3 $(40-60 \%)$ dan N (<40\%) dari hasil rata-rata potensi produktivitas tanaman padi di
Batu sebanyak $8 \mathrm{t} \mathrm{ha}^{-1}$ (Sareh dan Rayes, 2019), padi gogo di Pacitan sebanyak $6 \mathrm{t} \mathrm{ha}^{-1}$ (Syakir, 2019), rata-rata produktivitas padi nasional sebanyak 5,7 t ha-1 (Badan Pusat Statistik, 2018), produktivitas padi di Kalimantan Barat sebanyak 5 t ha- (Triono, 2016) dan produktivitas padi di Seram Utara Timur Kobi sebanyak 6,5 t ha-1 (Lailiyah et al., 2018) dengan varietas IR-64.

Penelitian ini menggunakan uji korelasi dan uji multiregresi. Korelasi merupakan teknik analisis yang termasuk dalam salah satu teknik pengukuran asosiasi/hubungan yang bermanfaat untuk mengukur kekuatan hubungan antara dua variabel (kadang lebih dari dua variabel) (Sungkawa, 2013). Analisis regresi adalah hubungan yang didapat dan dinyatakan dalam bentuk persamaan matematik yang menyatakan hubungan fungsional antar variabel-variabel (Widiyawati dan Setiawan, 2015). Secara umum model regresi dijabarkan sebagai berikut:

$\mathrm{Y}=\beta_{0}+\beta_{1} \mathrm{X}_{1}+\beta_{2} \mathrm{X}_{2}+\cdots+\beta_{\mathrm{k}} \mathrm{X}_{\mathrm{k}}+\varepsilon$

Keterangan:

$$
\begin{array}{cll}
\mathrm{Y} & : & \text { variabel terikat }(\mathrm{i}=1, \\
& 2, \ldots, \mathrm{n}) \\
\beta_{0} & : & \text { konstanta (intercept) } \\
\beta_{1}, \beta_{2}, \ldots, \beta_{\mathrm{k}} & : & \text { koefisien regresi } \\
\mathrm{X}_{1}, \mathrm{X}_{2}, \ldots, \mathrm{X}_{\mathrm{k}} & : & \text { variabel bebas } \\
\varepsilon & : & \text { Error }(\mathrm{i}=1,2,3, \ldots, \\
& \mathrm{n})
\end{array}
$$

Tabel 1. Kriteria lahan status hara N, P, K dan kelas kesesuaian lahan padi sawah.

\begin{tabular}{clccc}
\hline No & Unsur Hara & S1 & S2 & S3 \\
\hline 1. & N total $(\%)$ & Sedang $(0,21-0,50)$ & Rendah $(0,1-0,2)$ & Sangat Rendah $(<0,1)$ \\
2. & P tersedia $\left(\mathrm{mg} \mathrm{kg}^{-1}\right)$ & Tinggi $(26-33)$ & Sedang $(16-25)$ & Rendah $(10-15)$ \\
3. & K dd $\left(\mathrm{cmol} \mathrm{kg}^{-1}\right)$ & Sedang $(0,3-0,5)$ & Rendah $(0,1-0,2)$ & Sangat Rendah $(<0,1)$ \\
\hline
\end{tabular}

Sumber: Djaenuddin et al. (2003)

Tabel 2. Kelas kesesuaian produktivitas.

\begin{tabular}{clcc}
\hline No. & $\begin{array}{l}\text { Kelas Kesesuaian } \\
\text { Lahan }\end{array}$ & $\begin{array}{c}\text { \% Produktivitas Tanaman } \\
\text { (FAO, 1993) }\end{array}$ & $\begin{array}{c}\text { Nilai Produktivitas } \\
\text { TanamanPadi (t ha-1) }\end{array}$ \\
\hline 1. & S1 (Sangat Sesuai) & $80-100$ & $4,9-6,24$ \\
2. & S2 (Cukup Sesuai) & $60-80$ & $3,7-4,9$ \\
3. & S3 (Sesuai Marginal) & $40-60$ & $2,4-3,7$ \\
4. & N (Tidak Sesuai) & $<40$ & $<2,4$ \\
\hline
\end{tabular}

*Hasil dari rata-rata produktivitas berbagai daerah (Sumber: FAO, 1993) 


\section{Hasil dan Pembahasan}

\section{Pemetaan Kadar N, P dan K tanah}

Kadar N

Hasil penelitian menunjukkan bahwa $\mathrm{N}$ total di lokasi penelitian berada pada status sangat rendah dan rendah (Gambar 1 dan 2). Satuan Peta Lahan (SPL) 5 dan 8 berada pada kriteria sangat rendah $(<0,1 \%)$, sedangkan SPL yang lainnya berada pada kriteria rendah $(0,1-0,2$ $\%$ ). Rendahnya kadar $\mathrm{N}$ total di lokasi penelitian diduga karena penerapan sistem penggunaan lahannya. Lahan sawah irigasi menerapkan pengolahan tanah dengan cara perendaman sepanjang penanaman dan membutuhkan jumlah air yang besar, hal ini mengakibatkan kondisi anaerob bagi mikrooganisme dalam tanah yang dapat mengakibatkan bakteri penambat $\mathrm{N}$ sulit berkembang (Hameed et al., 2011). Menurut Rahayu (2010), lahan sawah tanah hujan dicirikan oleh sistem pengairan berasal dari air hujan, rendahnya kandungan hara, rendahnya kandungan bahan organik yang sulit dipertahankan dalam waktu jangka panjang, dan rendahnya produktivitas tanaman. Sawah tadah hujan memiliki faktor pembatas yang lebih kompleks dibanding sawah irigasi, diantaranya kesuburan tanah yang rendah dan masalah iklim yang mempengaruhi ketersediaan air (Kurniawan dan Widodo, 2009).

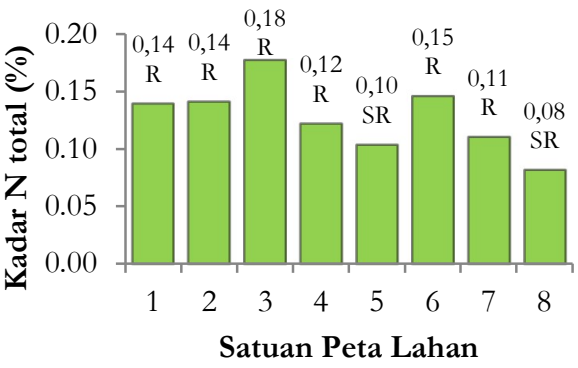

Gambar 1. Kadar N total. Keterangan: $\mathrm{SR}=$ Sangat Rendah $(<0,1 \%), \mathrm{R}=$ Rendah (0,1 - 0,2 \%), (Djaenuddin et al., 2003).

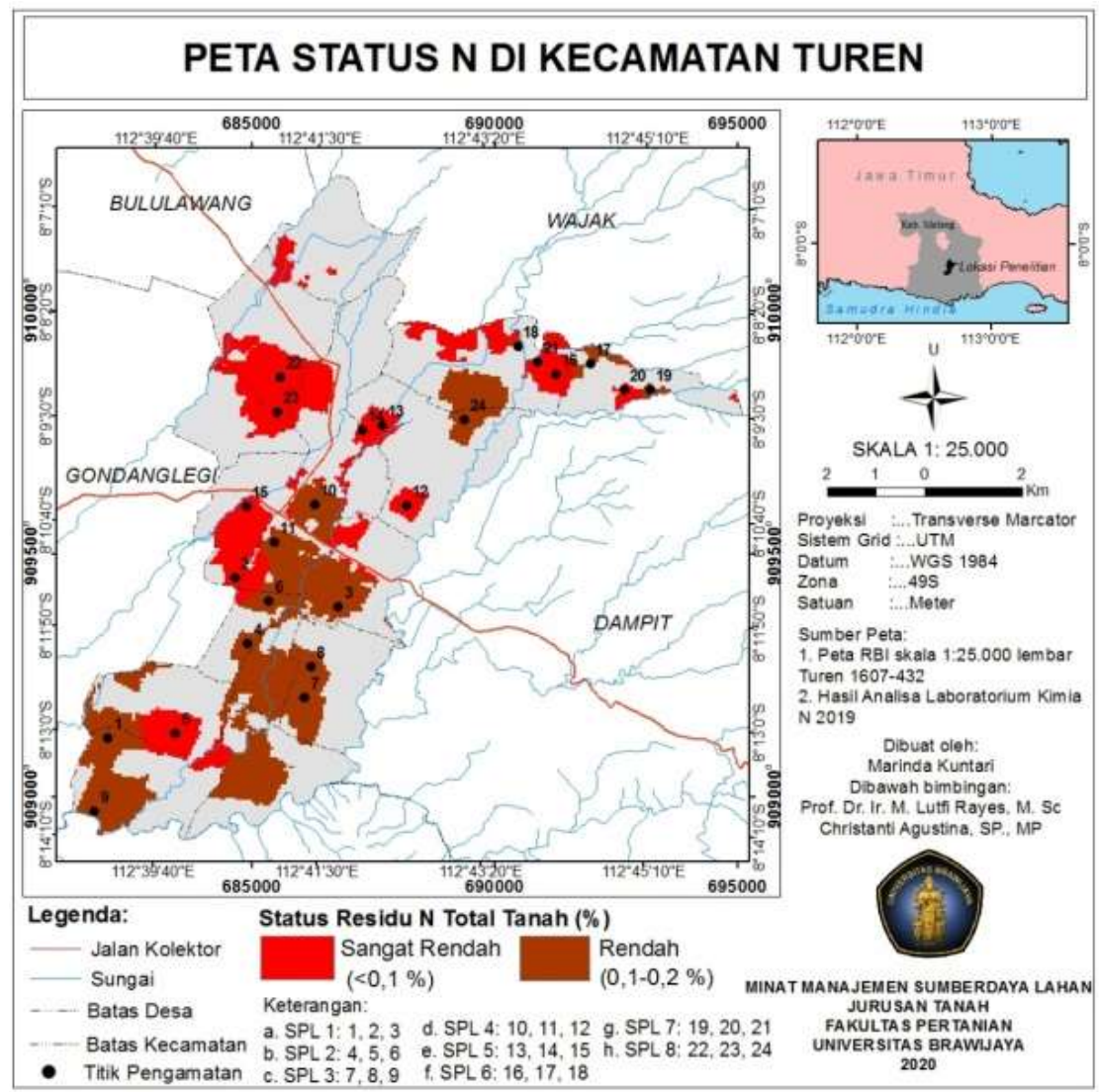

Gambar 2. Peta Status N total. 
Agustina et al. (2020) menyatakan bahwa kandungan bahan organik pada lahan sawah irigasi lebih tinggi daripada lahan sawah tadah hujan. Kondisi ini disebabkan oleh kondisi aerob pada lahan sawah tadah hujan meningkatkan dekomposisi bahan organik (Tangketasik et al., 2012) serta porositas tanah yang lebih tinggi pada sawah tadah hujan daripada sawah irigasi (Rosidha, 2020 belum dipublikasikan). Porositas tanah dan kadar hara $\mathrm{N}$ memiliki hubungan berbanding terbalik dimana semakin besar nilai porositas akan diikuti penurunan nilai kadar hara N. Hal ini sesuai dengan pendapat Goenadi (2006) bahwa sifat kimia tanah dapat dipengaruhi oleh sifat fisik tanah, yaitu tanah yang memiliki tingkat porositas baik dan tidak mengalami pemadatan tanah berpengaruh pada laju pencucian dalam tanah. Unsur hara dalam tanah akan dipertahankan sehingga tidak cepat hilang dan dapat dimanfaatkan oleh tanaman.

Kadar P

Hasil penelitian menunjukkan bahwa $\mathrm{P}$ tersedia di lokasi penelitian berada pada status sangat rendah dan rendah (Gambar 3 dan 4). Setiap Satuan Peta Lahan (SPL) memiliki perbedaan Kadar P tersedia, SPL 1 berada pada kriteria rendah $(<10 \mathrm{mg} \mathrm{kg-1})$ dan sisa SPL lainnya berada pada kriteria sangat rendah $(10-15 \mathrm{mg}$ $\mathrm{kg}^{-1}$ ). Status unsur hara P di lokasi penelitian termasuk dalam kriteria sangat rendah hingga rendah karena bahan induk tanah tersusun atas material tuf andesit dan lava basal. Material tuf andesit memiliki kadar $\mathrm{Al}$ dan $\mathrm{Fe}$, sedangkan material lava basal kaya akan $\mathrm{Mg}$ dan Fe. Melimpahnya unsur tersebut menyebabkan kadar P terikat, sehingga kadar P dalam tanah rendah (Sukarman dan Suhardjo, 1999).

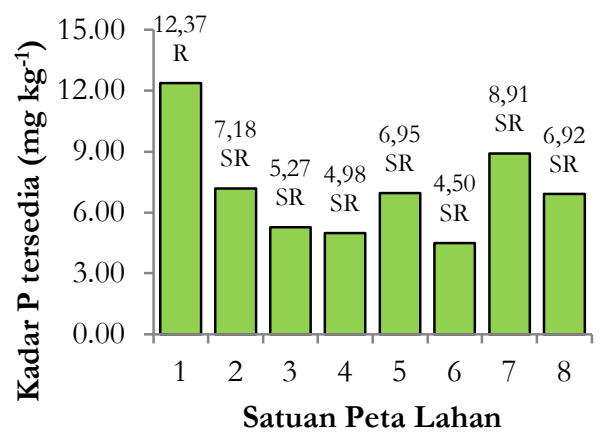

Gambar 3. Kadar P tersedia.

Keterangan: SR = Sangat Rendah $\left(<10 \mathrm{mg} \mathrm{kg}^{-1}\right), \mathrm{R}$ $=$ Rendah $\left(10-15 \mathrm{mg} \mathrm{kg}^{-1}\right)$ (Djaenuddin et al., 2003).

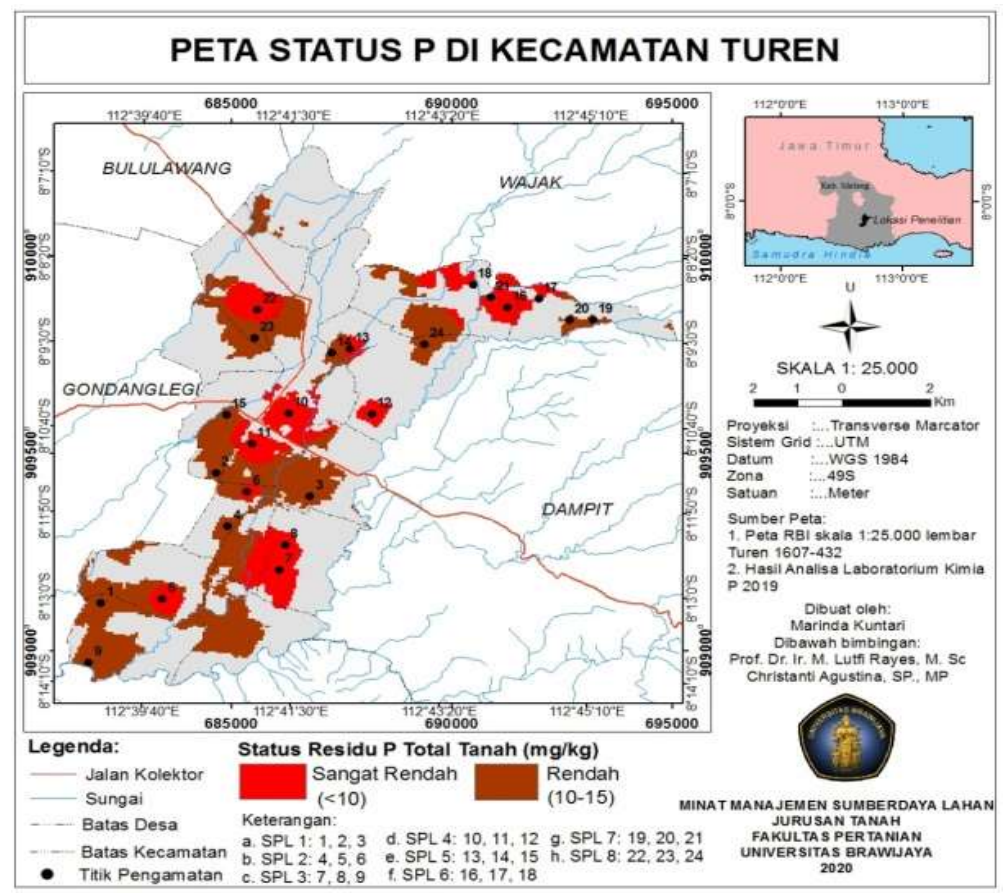

Gambar 4. Peta Status P tersedia 
Menurut Subiksa dan Setyorini (2009), fosfat alam adalah mineral apatit yang umumnya memiliki kelarutan yang rendah, sehingga ketersediaannya untuk tanaman sangat rendah. Kondisi $\mathrm{P}$ tanah yang sangat rendah tersedia untuk tanaman juga dipengaruhi oleh $\mathrm{pH}$. Hasil analisa $\mathrm{pH}$ di lokasi penelitian berada dalam kisaran 5,9-6,19 menunjukkan bahwa keadaan derajat keasaman tanah di akhir tanaman padi sawah adalah asam. Fosfor tersedia dalam jumlah yang tinggi bagi tanaman pada kondisi tanah dengan $\mathrm{pH}$ berkisar antara 6,5 - 7,5 (Hanafiah, 2005).

Kadar K

Hasil penelitian menunjukkan bahwa $K_{\mathrm{dd}}$ di lokasi penelitian berada pada status rendah, sedang dan tinggi (Gambar 5 dan 6). Satuan Peta Lahan (SPL) 4 berada pada kriteria rendah $(0,2$ - 0,3 $\left.\mathrm{cmol} \mathrm{kg}^{-1}\right)$, SPL 3 berada pada kriteria sedang $\left(0,3-0,5 \mathrm{cmol} \mathrm{kg}^{-1}\right)$ dan SPL lainnya berada pada kriteria tinggi $\left(0,5-1 \mathrm{cmol} \mathrm{kg}^{-1}\right)$. Perbedaan kelas kriteria Kalium tanah diduga karena adanya perbedaan input pupuk dan pengembalian jerami dan bahan induk tanah. Berdasarkan data primer wawancara petani
(2019) diperoleh hasil bahwa pada awal tanam input pupuk paling rendah berada pada SPL 4 sehingga kondisi akhir tanam SPL 4 memiliki Kadar $\mathrm{K}_{\text {dd }}$ paling rendah. Ariawan et al. (2016) menyebutkan kapasitas input kalium tanah, ketidakcukupan pemberian pupuk kalium anorganik, kecilnya masukan kalium dalam air irigasi, rendahnya efisiensi penyerapan pupuk merupakan penyebab rendahnya kadar K dalam tanah.

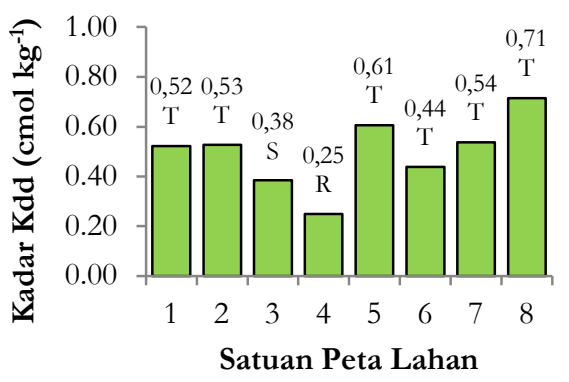

Gambar 5. Kadar $K_{\text {dd. }}$. Keterangan: $\mathrm{R}=\operatorname{Rendah}\left(0,2-0,3 \mathrm{cmol} \mathrm{kg}^{-1}\right), \mathrm{S}=$ Sedang $\left(0,3-0,5 \mathrm{cmol} \mathrm{kg}^{-1}\right), \mathrm{T}=$ Tinggi $(0,5-1$ $\mathrm{cmol} \mathrm{kg}^{-1}$ ) (Djaenuddin et al., 2003).

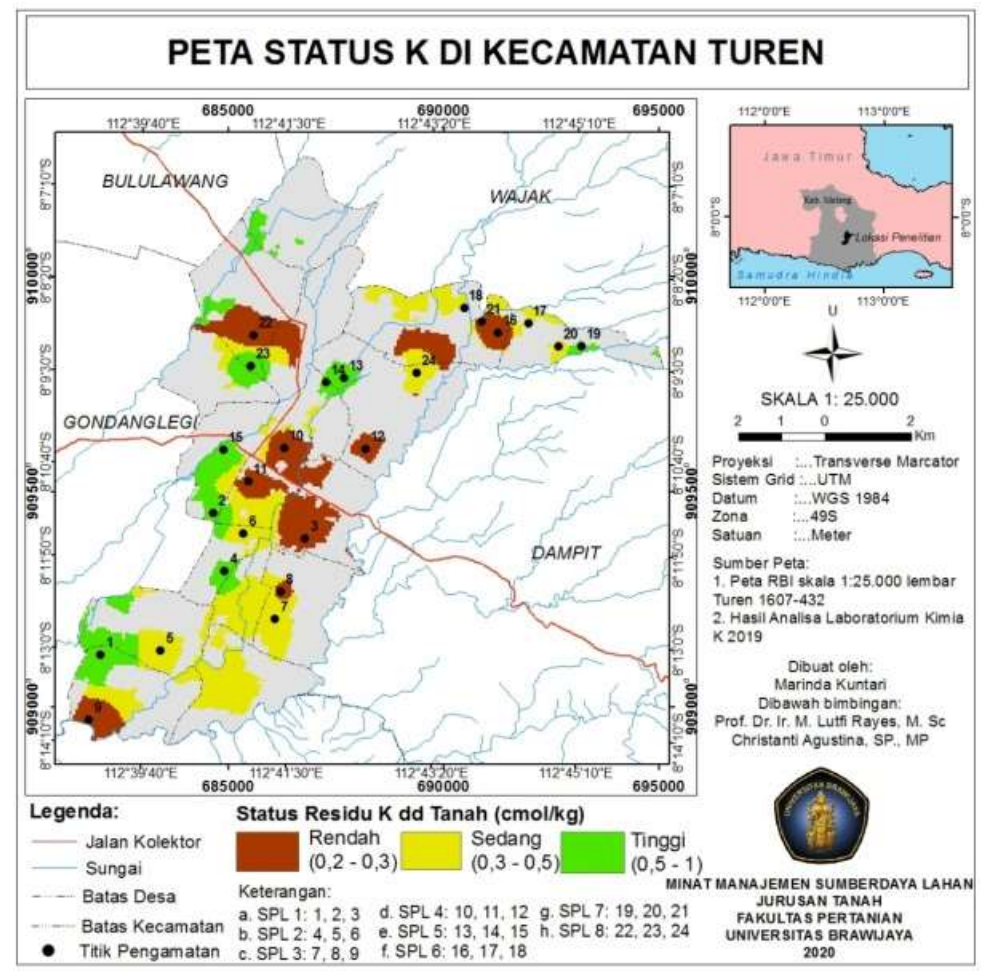

Gambar 6. Peta Status $K_{d d}$. 
Selain itu, bahan induk tanah juga memberikan pengaruh terhadap ketersediaan $\mathrm{K}$ dalam tanah. Kalium terdapat pada mineral-mineral primer tanah seperti mineral feldspar, mika dan lainlain, sehingga ditemukan banyak dalam tanah, tetapi sebagian kecil yang dapat dimanfaatkan oleh tanaman yaitu $\mathrm{K}$ yang larut dalam air (Juarti, 2016). Umumnya, kadar K pada tanah sawah berkisar sedang - tinggi (Agoesdy et al., 2019). Pada SPL 8 termasuk kriteria tinggi hal ini bisa disebabkan oleh ketersediaan kalium bertahan empat tahun setelah aplikasi pemupukan dan dapat terakumulasi pemupukan musim berikutnya (Antunovic et al., 2012 dan Rastija et al., 2014).

\section{Hubungan unsur hara $\mathbf{N}$ dengan produktivitas tanaman}

Penilaian kesesuaian lahan untuk unsur hara $\mathrm{N}$ didominasi masuk kedalam kelas kriteria S2 selaras dengan kelas kriteria produktivitas yaitu S2 (Tabel 2). Besar kecilnya produksi padi sawah tergantung pada faktor-faktor produksi yang digunakan, antara lain luas lahan, pupuk, tenaga kerja, benih dan pestisida (Makruf et al., 2011).
Berdasarkan wawancara, penggunaan pupuk di setiap SPL menggunakan pupuk Urea, ZA dan Phonska dengan Kadar yang belum seseuai dengan kebutuhan tanaman padi yaitu dalam kisaran $61-122 \mathrm{~kg} \mathrm{ha}{ }^{-1}$. Menurut Badan Litbang Pertanian (2014), kebutuhan unsur hara N untuk tanaman padi berkisar $90-120 \mathrm{~kg} \mathrm{ha}^{-1}$ dan menurut rekomendasi Permentan No. 40 (2007) unsur hara $\mathrm{N}$ untuk tanaman padi paling optimal berjumlah $115 \mathrm{~kg} \mathrm{ha}^{-1}$. Pemupukan yang dilakukan pada awal tanam dapat menyebabkan kondisi pada akhir tanam berkurang karena terserapnya unsur hara terhadap tanaman dan potensi dari kehilangan unsur hara yang diakibatkan oleh sifat yang lain. Pupuk N diperlukan untuk pertumbuhan tanaman sepanjang musim (BPTP Bengkulu, 2009) sehingga dengan Kadar unsur hara $\mathrm{N}$ akhir tanam S2 dapat menyebabkan produktivitas S2. Kesesuaian unsur hara $\mathrm{N}$ yang semulanya S2 dapat ditingkatkan menjadi S1 salah satunya melalui pemeliharaan pemupukan agar Kadarnya meningkatkan dan mampu memenuhi kebutuhan tanaman sehingga kesesuaian produktivitas menjadi S1.

Tabel 2. Kesesuaian produktivitas di setiap SPL berdasarkan kadar N tanah.

\begin{tabular}{ccccc}
\hline SPL & $\begin{array}{c}\mathbf{N} \\
(\mathbf{\%})\end{array}$ & $\begin{array}{c}\text { Kesesuaian Hara } \\
\text { Tersedia }\end{array}$ & $\begin{array}{c}\text { Produktivitas } \\
\left(\mathbf{t ~ h a}^{-1} \mathbf{)}\right.\end{array}$ & $\begin{array}{c}\text { Kesesuaian } \\
\text { Produktivitas }\end{array}$ \\
\hline 1. & 0,14 & S2 & 4,71 & S2 \\
2. & 0,14 & S2 & 4,72 & S2 \\
3. & 0,18 & S2 & 4,31 & S2 \\
4. & 0,12 & S2 & 4,31 & S2 \\
5. & 0,10 & S3 & 4,72 & S2 \\
6. & 0,15 & S2 & 5,23 & S2 \\
7. & 0,11 & S2 & 4,71 & S2 \\
8. & 0,08 & S3 & 4,35 & \\
\hline
\end{tabular}

\section{Hubungan unsur hara $P$ dengan produktivitas tanaman}

Penilaian kesesuaian lahan untuk unsur hara $\mathrm{P}$ didominasi masuk kedalam kelas kriteria S3 yang tidak selaras dengan kelas produktivitas yaitu S2 (Tabel 3). Berdasarkan wawancara, penggunaan pupuk di setiap SPL menggunakan pupuk SP-36 dan Phonska dengan Kadar yang belum sesuai dengan kebutuhan tanaman padi yaitu dalam kisaran 15 - $48 \mathrm{~kg} \mathrm{ha}^{-1}$. Menurut Badan Litbang Pertanian (2014), kebutuhan unsur hara P untuk tanaman padi berkisar $30-60 \mathrm{~kg} \mathrm{ha}^{-1}$ tetapi menurut rekomendasi Permentan No. 40 (2007) unsur hara $P$ untuk tanaman padi paling optimal berjumlah $27 \mathrm{~kg} \mathrm{ha}^{-1}$. Beberapa SPL di lokasi penelitian sudah terpenuhi kebutuhan $\mathrm{P}$ untuk tanaman padi akan tetapi beberapa SPL lainnya masih belum terpenuhi. Pada fase awal pertumbuhan, fosfor dibutuhkan tanaman untuk perkembangan akar, membentuk anakan dan munculnya bunga (BPTP Bengkulu, 2009), sehingga pupuk $\mathrm{P}$ diberikan pada awal pertumbuhan tanaman. Kelas kesesuaian lahan S3 untuk unsur hara $\mathrm{P}$ disebabkan oleh nilai $\mathrm{pH}$ 
di lokasi penelitian tergolong asam dan bahan induk tanah yang tersusun oleh tuf andesit dan mengandung $\mathrm{Al}$ dan $\mathrm{Fe}$. Kandungan $\mathrm{Al}$ dan Fe dalam tanah dapat mengikat unsur hara $\mathrm{P}$ dalam koloid tanah sehingga tidak tersedia untuk tanaman padi (Sukarman dan Suhardjo, 1999). Kesesuaian unsur hara $\mathrm{P}$ yang tergolong S3 dapat ditingkatkan menjadi S1 dengan pengapuran dan penambahan dosis pupuk yang sesuai anjuran.

\section{Hubungan unsur hara $K$ dengan produktivitas tanaman}

Penilaian kesesuaian lahan untuk unsur hara $\mathrm{K}$ didominasi masuk kedalam kelas S1 yang tidak selaras dengan kelas produktivitas yaitu S2 (Tabel 4). Berdasarkan wawancara, penggunaan pupuk di setiap SPL menggunakan pupuk $\mathrm{KCl}$ dan Phonska dengan Kadar yang belum sesuai dengan kebutuhan tanaman padi yaitu dalam kisaran $27-75 \mathrm{~kg} \mathrm{ha}^{-1}$. Menurut Badan Litbang Pertanian (2014), kebutuhan unsur hara P untuk tanaman padi berkisar $30-50 \mathrm{~kg} \mathrm{ha}^{-1}$ dan menurut rekomendasi Permentan No. 40 (Departemen Pertanian, 2007), unsur hara P untuk tanaman padi paling optimal berjumlah $30 \mathrm{~kg} \mathrm{ha}^{-1}$.

Beberapa SPL di lokasi penelitian sudah terpenuhi kebutuhan $\mathrm{K}$ untuk tanaman padi akan tetapi ada SPL yang hampir terpenuhi. Penyebab kesesuaian unsur hara K tergolong S1 karena pemupukan yang sudah sesuai dengan rekomendasi dan adanya pengembalian jerami ke lahan. Menurut Conyers et al. (2003), dalam pengelolaan hara $\mathrm{K}$, sangat relevan dengan pemanfaatan sisa-sisa tanaman atau limbah pertanian, sebanyak $89 \% \mathrm{~K}$ yang diambil tanaman padi berada dalam jerami. Pengembalikan jerami ke lahan pertanian sangat bermanfaat dalam mempertahankan kesuburan tanah. Unsur $\mathrm{K}$ dalam jerami padi cepat mengalami pelarutan saat terjadi pelapukan dan dekomposisi. Pembenaman jerami padi dalam tanah yang tergenang dalam waktu 30 hari dapat melepaskan hampir seluruh unsur $\mathrm{K}$ dalam jerami (De Datta dan Mikkelsen, 1985). Peningkatan jumlah gabah per malai dan gabah bernas sangat bergantung pada asupan unsur hara $\mathrm{K}$ yang diberikan pada tanaman padi (Makruf et al., 2011).

Tabel 3. Kesesuaian produktivitas di setiap SPL berdasarkan kadar P tanah.

\begin{tabular}{ccccc}
\hline SPL & $\begin{array}{c}\mathbf{P} \\
\left(\mathbf{m g ~ k g}^{-1}\right)\end{array}$ & $\begin{array}{c}\text { Kesesuaian Hara } \\
\text { Tersedia }\end{array}$ & $\begin{array}{c}\text { Produktivitas } \\
\left(\mathbf{t ~ h a}^{-\mathbf{1}}\right)\end{array}$ & $\begin{array}{c}\text { Kesesuaian } \\
\text { Produktivitas }\end{array}$ \\
\hline 1. & 12,37 & $\mathrm{~S} 3$ & 4,71 & $\mathrm{~S} 2$ \\
2. & 7,18 & $\mathrm{~S} 3$ & 4,72 & $\mathrm{~S} 2$ \\
3. & 5,27 & $\mathrm{~S} 3$ & 4,31 & $\mathrm{~S} 2$ \\
4. & 4,98 & $\mathrm{~S} 3$ & 4,31 & $\mathrm{~S} 2$ \\
5. & 6,95 & $\mathrm{~S} 3$ & 4,72 & $\mathrm{~S} 2$ \\
6. & 4,50 & $\mathrm{~S} 3$ & 5,23 & $\mathrm{~S} 1$ \\
7. & 8,91 & $\mathrm{~S} 3$ & 4,71 & $\mathrm{~S} 2$ \\
8. & 6,92 & $\mathrm{~S} 3$ & 4,35 & $\mathrm{~S} 2$ \\
\hline
\end{tabular}

Tabel 4. Kesesuaian produktivitas di setiap SPL berdasarkan kadar K tanah

\begin{tabular}{ccccc}
\hline SPL & $\begin{array}{c}\mathbf{K} \\
(\mathbf{c m o l ~ k g} \mathbf{- 1})\end{array}$ & $\begin{array}{c}\text { Kesesuaian Hara } \\
\text { Tersedia }\end{array}$ & $\begin{array}{c}\text { Produktivitas } \\
(\mathbf{t ~ h a - 1})\end{array}$ & $\begin{array}{c}\text { Kesesuaian } \\
\text { Produktivitas }\end{array}$ \\
\hline 1. & 0,52 & S1 & 4,71 & S2 \\
2. & 0,53 & S1 & 4,72 & S2 \\
3. & 0,38 & S1 & 4,31 & S2 \\
4. & 0,25 & S2 & 4,31 & S2 \\
5. & 0,61 & S1 & 4,72 & S2 \\
6. & 0,44 & S1 & 5,23 & S2 \\
7. & 0,54 & S1 & 4,71 & S2 \\
8. & 0,71 & S1 & 4,35 & \\
\hline
\end{tabular}




\section{Hubungan unsur hara $\mathbf{N}, P$ dan $K$ dengan produktivitas tanaman}

Hasil uji multiregresi nilai $\mathrm{R}^{2}=0,0826$ yang berarti lemah karena mendekati 0 (Tabel 5).

$$
\mathrm{y}=3,859+3,472 \mathrm{X} 1+(-0,004 \mathrm{X} 2)+0,733 \mathrm{X} 3
$$

Nilai X1 merupakan variabel unsur hara $N$, X2 merupakan variabel unsur hara $\mathrm{P}$, dan X3 merupakan variabel unsur hara K. Persamaan tersebut dapat diartikan bahwa (1) produktivitas padi akan meningkat sebesar 3,472 ( $\left.\mathrm{t} \mathrm{ha}^{-1}\right)$, jika unsur hara $\mathrm{N}$ naik $1(\%)$ dengan asumsi variabel lain tetap; (2) produktivitas padi akan menurun sebesar 0,004 (t ha-1) jika unsur hara $P$ naik 1 (mg kg-1), dengan asumsi variabel lain tetap; (3) produksi padi akan meningkat sebesar 0,733 (t $\left.\mathrm{ha}^{-1}\right)$, jika unsur hara $\mathrm{K}$ naik $1\left(\mathrm{cmol} \mathrm{kg}^{-1}\right)$ dengan asumsi variabel lain tetap; (4) nilai konstanta dari produktivitas padi sebesar 3,859 dimana jika mengabaikan variabel lain, potensi produktivitas padi sebesar 3,859 $\mathrm{t} \mathrm{ha}^{-1}$.

Tabel 5. Uji Multiregresi.

\begin{tabular}{|c|c|c|c|c|c|}
\hline \multicolumn{6}{|c|}{ Coefficients $^{\mathrm{a}}$} \\
\hline & & \multicolumn{2}{|c|}{ Unstandardized Coefficients } & \multirow[b]{2}{*}{ t Stat } & \multirow[b]{2}{*}{$P$-value } \\
\hline & & Coefficient & Std. Error & & \\
\hline \multirow[t]{4}{*}{1} & Intercept & 3,849 & 1,325 & 2,906 & 0,044 \\
\hline & $\mathrm{N}(\%)$ & 3,472 & 6,372 & 0,545 & 0,615 \\
\hline & $\mathrm{P}\left(\mathrm{mg} \mathrm{kg}^{-1}\right)$ & $-0,004$ & 0,064 & $-0,055$ & 0,959 \\
\hline & $\mathrm{K}\left(\mathrm{cmol} \mathrm{kg}^{-1}\right)$ & 0,733 & 1,445 & 0,507 & 0,639 \\
\hline
\end{tabular}

\section{Kesimpulan}

Kadar unsur hara $\mathrm{N}$ dan $\mathrm{P}$ berada pada status sangat rendah hingga rendah sedangkan unsur hara $\mathrm{K}$ berada pada status rendah hingga tinggi. Peta sebaran unsur hara di lokasi penelitian Kecamatan Turen pada unsur hara N memiliki luas status rendah $53,3 \%$ dan sangat rendah 46,7\%. Sebaran unsur hara P memiliki luas status rendah $60,2 \%$ dan sangat rendah $39,3 \%$. Sebaran unsur hara $\mathrm{K}$ memiliki luas status tinggi 29,8\%, sedang 44,1\% dan rendah 26,1\%. Hubungan kadar unsur hara N, P dan K akhir tanam dengan produktivitas tanaman ditunjukkan dengan hasil uji multiregresi memiliki nilai $\mathrm{R}^{2}=0,0826$ yang berarti lemah karena mendekati 0 .

\section{Ucapan Terima Kasih}

Penulis mengucapkan terima kasih kepada Universitas Brawijaya yang telah mendanai penelitian ini dalam skema Hibah Peneliti Pemula (Dana PNBP Universitas Brawijaya-DIPA-042.01.2.400919/ 2019). Penulis juga mengucapkan terima kasih sebesar-besarnya kepada masyarakat di Kecamatan Turen atas bantuan yang diberikan selama kegiatan penelitian.

\section{Daftar Pustaka}

Agoesdy, R., Hanum, H., Rauf, A. dan Harahap, F.S. 2019. Status hara fosfor dan kalium di lahan sawah di Kecamatan Tanjung Morawa Kabupaten Deli Serdang. Jurnal Tanah dan Sumberdaya Lahan 6(2): 1387-1390.

Agustina, C., Rayes, M.L., Kusumarini, N. dan Sudharta, K.A. 2020. Pemetaan bahan organik tanah pada sawah irigasi dan tadah hujan di Kecamatan Turen, Malang. Jurnal Tanah dan Sumberdaya Lahan 7(1): 69-75.

Antunovic, M., Rastija M., Sudaric, A., Varga, I. and Jovic, J. 2012. Response of soybean to phosphorus fertilization under drought stress conditions. Növénytermelés 61(2): 117-120.

Ariawan, A., Thaha, R. dan Prahastuti, S.W. 2016. pemetaan status hara kalium pada tanah sawah di Kecamatan Balinggi, Kabupaten Parigi Moutong, Sulawesi Tengah. Jurnal Agrotekbis 4(1) : 43-49.

Badan Litbang Pertanian. 2014. Jajar Legowo. Badan Penelitian dan Pengembangan Pertanian. Kementerian Pertanian.

Badan Pusat Statistik. 2014. Konsumsi beras nasional (ton) 2013. Tersedia pada: http://www.bps.go.id / site/result.

Badan Pusat Statistik. 2018. Kecamatan Turen dalam Angka. https://malangkab.bps.go.id.

Badan Pusat Statistik. 2019. Kecamatan Turen dalam Angka. https://malangkab.bps.go.id. 
Balai Pengkajian Teknologi Pertanian. 2009. Teknologi Budidaya Padi Sawah dengan Pendekatan PTT. Kementerian Pertanian.

BPTP Bengkulu. 2009. Panduan Teknologi Mendukung Program SLPTT Padi. Balai Pengkajian Teknologi Pertanian Bengkulu.

Bray, R.H. and Kurtz, L.T. 1945. Determination of total organic and available forms of phosphorus in soils. Soil Science 59(1): 39 - 46.

Bremner, J.M. 1960. Determination of Nitrogen in Soil by The Kjeldahl Method. The Journal of Agricultural Science 55(1): 11-33.

Conyers, M.K., Heenan, D.P., Mcghie, W.J. and Poile, G.P. 2003. Amelioration of acidity with time by limestone under contrasting tillage. Soil \& Tillage Research $72: 85-94$.

De Datta, S.K. and Mikkelsen, D.S. 1985. Potassium nutrition of rice. pp. 665-699. In Munson (Ed.). Potassium Nutrition of Rice.

Departemen Pertanian. 2007. Peraturan Menteri Pertanian No 40/Permentan/OT.140/8/2007. Kementerian Pertanian.

Djaenuddin, D., Marwan, H., Subagyo, H., Mulyani, A. dan Suharta, N. 2003. Kriteria Kesesuaian Lahan Untuk Komoditas Pertanian. Pusat Penelitian Tanah dan Agroklimat. Badan Penelitian dan Pengembangan Pertanian : Bogor.

Food and Agriculture Organization (FAO). 1993. A Framework for Land Evaluation. Prepared by Soil Reseources Management and Conservation Service Land and Water development Division, FAO Soil Buletin No.32. FAO-UNO, Rome.

Goenadi, D.H. 2006. Pupuk dan Teknologi Pemupukan Berbasis Hayati. Dari Cawan Petri ke Lahan Petani. Yayasan Idetama. Jakarta.

Hameed, K.A., Jaber, F.A., Hadi, A.Y., Elewi, J.A.H. and Uphoff, N. 2011. Application of system of rice intensification methods on productivity of jasmine rice variety in Southern Iraq. Jordan Journal of Agricultural Sciences 7(3): 474-481.

Hanafiah, K.A. 2005. Dasar-Dasar Ilmu Tanah. Jakarta : PT. Raja Grafindo Persada.

Juarti, J. 2016. Analisis indeks kualitas tanah andisol pada berbagai penggunaan lahan di Desa Sumber Brantas Kota Batu. Jurnal Pendidikan Geografi 21(2): 58-71.

Kurniawan, Y. dan Widodo, W. 2009. Keragaan empat varietas lokal padi pada pemberian amelioran ultisol, abu sekam padi dan dolomit di lahan gambut. Akta Agrosia 12(1): 45-50.

Lailiyah, N., Timisela, N.R. dan Kaplale, R. 2018. Analisis produksi padi sawah (Oryza sativa L) tadah hujan di Desa Lea Wai Kecamatan Seram Utara Timur Kobi. Agrilan: Jurnal Agribisnis Kepulauan 5(2): 151-165.

Makruf E., Oktavia, Y., dan Putra, W.E. 2011. Faktor-faktor yang mempengaruhi Produksi Padi
Sawah di Kabupaten Seluma, Bengkulu. Balai Pengkajian Teknologi Pertanian Bengkulu.

Notohadiprawiro, T., Soekodarmodjo, S. dan Sukana, E. 2006. Pengelolaan Kesuburan Tanah dan Peningkatan Efisiensi Pemupukan. Yogyakarta: Universitas Gadjah Mada.

Rahayu. 2010. Budidaya Padi Organik. Surakarta : PT. Sekawan Cipta Karya.

Rastija M., Jovic, J., Iljkic, D., Kovacevic, V. and Rastija, D. 2014. Response of winter wheat to ameliorative phosphorus fertilization, In: Proceedings of the 49th Croatian and 9th International Symposium on Agriculture, February 16-21, Dubrovnik (Maric S. and Loncaric Z. editors), Faculty of Agriculture in Osijek, p. $412-415$.

Sareh, A.F.F. dan Rayes, M.L. 2019. Evaluasi Kesesuaian Lahan Padi Pada Sawah Irigasi di Kecamatan Junrejo Kota Batu. Jurnal Tanah dan Sumberdaya Lahan 6(1): 1193-1200.

Sharma, P.K. and Bhushan, L. 2001. Physical characterization of a soil amended with organic residues in a rice-wheat cropping system using a single value soil physical index. Soil and Tillage Research 60(3-4): 143-152.

Subiksa, I.G.M. dan Setyorini, D. 2009. Pemanfaatan Fosfat Alam untuk Lahan Sulfat Masam. Dalam: Fosfat Alam: Pemanfaatan Fosfat Alam Yang Digunakan Langsung Sebagai Pupuk Sumber P. Sastramihardja, H., Manalu, F. dan Aprillani, S.E. (eds). Balai Penelitian Tanah. Bogor: Balai Penelitian Tanah. Badan Penelitian dan Pengembangan Pertanian. Bogor. pp 62-83.

Sukarman, D.D. dan Suhardjo, H. 1999. Karakteristik tanah berbahan induk batuan andesit yang tertutup abu volkan dan tufa batu apung di Gunung Kimangbuleng, Flores, NTT. Jurnal Tanah dan Iklim 1(17): 14-26.

Sungkawa, I. 2013. Penerapan analisis regresi dan korelasi dalam menentukan arah hubungan antara dua faktor kualitatif pada tabel kontigensi. Jurnal Matematika Statistik 13(1): 33-41.

Syakir. 2019. Balai Besar Penelitian Tanaman Padi Balitbangtan Kementerian Pertanian. Tersedia pada : http:/ /bbpadi.litbang.pertanian.go.id.

Tangketasik, A., Wikarniti, N.M., Soniari, N.N. dan Narka, I.W. 2012. Kadar bahan organik tanah pada tanah sawah dan tegalan di Bali serta hubungannya dengan tekstur tanah. Agrotrop 2(2): 101-107.

Triono. 2016. Dinas Pertanian Tanaman Pangan dan Hortikultura. http:/ / distan.kalbarprov.go.id.

Widiyawati, W. dan Setiawan, S. 2015. Analisis faktor-faktor yang mempengaruhi tingkat produksi padi dan jagung di Kabupaten Lamongan. Jurnal Sains dan Seni ITS 4(1): 165 171. 